\title{
Resenha da obra: Ruptura - A crise da democracia liberal de Manuel Castels
}

\author{
Caroline Rodrigues da Silva*
}

A intensificação das manifestações sociais é uma marca deste século, que demonstra o ocaso da democracia liberal, sobretudo o desprezo a uma de suas regras de ouro - o sistema de representação. Muito tem se falado e escrito sobre esse fenômeno - e há uma vasta literatura sobre essa questão -, no entanto chama atenção o livro Ruptura - A crise da democracia liberal, publicado no Brasil no final de 2018 pela editora Zahar. Neste curto trabalho de 150 páginas, o autor Manuel Castells procura, a partir de eventos que atacam os pilares da democracia liberal contemporânea nos países da Europa e dos Estados Unidos, oferecer as causas do ocaso, citado no início deste parágrafo. Este fenômeno tem se tornado um pesadelo para as elites políticas de todo o mundo e também para a esquerda social, já que ambos aderem cada dia mais aos princípios da competitividade e se distanciam da solidariedade.

No Brasil, as Jornadas de Junho de 2013, o impeachment da ex-presidente Dilma Rousseff em 2016 e o número de votos nulos, brancos e abstenções no segundo turno das eleições presidenciais de 2018 são sintomas do quanto a democracia liberal está fatigada em nossas paragens. O cenário político brasileiro mais recente só aprofunda essa tendência, já que está marcado pelo retorno dos militares como atores políticos, pela supervalorização do poder judiciário em detrimento dos demais, pela deslegitimação da participação social na gestão pública e pela perseguição às instituições de educação, ao mesmo tempo em que se defende a lógica da punição e do encarceramento. Todas essas expressões antidemocráticas contidas na nossa democracia fazem com que alguns já digam que estamos diante do "fim da Nova República iniciada em 1985" (CHIRIO, 2018). Ao menos para aqueles que valorizam os princípios da democracia e que reconhecem que, num país tão desigual como o Brasil ela é resultado de muitas lutas sociais e o único caminho para que tais lutas sigam existindo, o livro é uma leitura necessária.

Embora o autor não trate das experiências democráticas na América Latina entendemos que o Brasil está imerso no processo de "ruptura" que Manuel Castells trata, ou seja, processo este em que governantes e governados já não estabelecem vínculos e se veem diante de uma crise de legitimidade política.

Manuel Castells é um sociólogo espanhol que, nos últimos anos, dedicou-se ao estudo dos impactos da era da informação sobre a economia, a cultura e a sociedade, assim como desenvolveu importantes análises sobre as sociedades conectadas em redes. No Brasil, é conhecido desde a década de 1980 através do livro "A Questão Urbana", que se tornou uma referência para sociólogos, urbanistas, geógrafos, assistentes sociais, historiadores, entre outros.

\footnotetext{
*Doutoranda do Programa de Estudos Pós-Graduados em Serviço Social da PUC-SP, mestre em Serviço Social pela UERJ (2013) e graduada em Serviço Social pela Universidade Federal Fluminense (2010). É assistente social da ONG FASE - Federação dos Órgãos para Assistência Social e Educacional.

${ }^{1}$ Agradeço a Aércio Barbosa de Oliveira pela gentil conversa que contribuiu sobremaneira para este texto.

Foi escrito na França entre 1969 e 1971 e publicado pela primeira vez em língua portuguesa em 1983. Sua importância deve-se ao fato de ter colocado a questão urbana e as lutas urbanas no centro do processo de urbanização capitalista, evidenciando suas contradições. À época, sua análise foi orientada pela perspectiva marxista althuusseriana que, pelo seu excessivo formalismo, posteriormente rendeu ao autor inúmeras críticas.
} 
No livro, que é objeto desta resenha, o autor nos apresenta uma análise global da crise democrática e demonstra que além das particularidades de cada sociedade estamos diante do colapso gradual de um modelo de representação, cujas consequências ainda não sabemos quais serão.

O perigo maior para manutenção da hegemonia dos globalizadores parece não ser a rebelião direta, mas a saída do sistema. O que se teme não é o desafio direto à democracia por parte de ideologias neofacistas deslegitimadoras da história (ao menos na Europa atual), mas a deserção de amplos setores da sociedade ante uma democracia que não nos representa, suscitando a possibilidade de uma busca incerta de novas formas de representação. (CASTELLS, 2018, p.78)

O livro está dividido em quatro capítulos, a saber: 1) A crise de legitimidade política: não nos representam; 2) Terrorismo global: a política do medo; 3) A rebelião das massas e o colapso de uma ordem política; 4) Espanha: movimentos sociais, fim do bipartidarismo e crise do estado. A leitura é agradável e traz uma novidade do ponto de vista da exposição dos dados, já que o autor optou por suprimir do texto tabelas, gráficos, quadros e referências, e os disponibilizou no site www.zahar.com.br/livro/ruptura.

Ao analisar os fatores da crise da democracia liberal, Castells toma por base a memorável frase de Winston Churchill, primeiro-ministro britânico durante a Segunda Guerra Mundial, segundo o qual "a democracia é a pior forma de governo, com exceção de todas as outras formas que foram experimentadas de tempos em tempos". Isso posto, Castells defende que as "raízes da ira" contra a democracia liberal estão: I) na crise do Estado-Nação provocada pelo
processo de globalização da economia e
pelo desenvolvimento das tecnologias da
informação a partir dos anos 1970, crise
esta que deu lugar ao que o autor chamou
"Estado-Rede", ou seja os Estados-Nações
passaram a se articular institucionalmente
numa rede supranacional, cuja União Europeia
é o exemplo mais forte. Particularmente
na Europa de tantas guerras, onde o
nacionalismo está arraigado na sociedade, a
construção da União Europeia como projeto
político, econômico e institucional não se deu

sem conflitos. A partir de dados de pesquisa desenvolvida entre os anos de 2012 e 2016 o autor identifica três falhas principais no seu processo de construção. A primeira é a falta de uma identidade comum entre os países membros, a qual levaria à formação de uma "autodefinição por exclusão do outro" - o outro que vem da África, do Oriente Médio, da América Latina, enfim, aqueles que não têm uma "identidade-projeto", que não sonham em ter uma Europa para os Europeus. A segunda falha trata-se da ausência de participação social na construção da instância supranacional, assim como na escassa participação popular na Comissão Europeia, onde o voto de países mais ricos como Alemanha e França sempre tiveram maior peso. A terceira falha decorre da segunda e ajuda a compreendermos a crise da democracia liberal, já que a União Europeia aumentou ainda mais o distanciamento entre os cidadãos e os seus governos. Lembremos que a governança da Comissão Europeia não tem controle democrático, pelo contrário, está apoiada na tecnocracia e em um funcionalismo privilegiado.

É importante destacar que Castells, apesar das críticas à União Europeia, se posiciona claramente a favor dela ao dizer que:

Subjetivamente compartilho dos ideais que guiaram este projeto europeu, os que, ao contrário do que declarou a esquerda dogmática, não se reduziram a "Europa do capital", embora, tratando-se de economias capitalistas, é óbvio que não deixaram de sê-lo no âmbito europeu. Na verdade, a social-democracia foi a principal força política impulsionadora do projeto. E países do sul (Grécia, Espanha e Portugal) se beneficiaram enormemente de sua incorporação à União, afastando definitivamente os perigos do autoritarismo e de golpes militares. (CASTELLS, 2018,p.86)

III) outro elemento chave da crise da democracia liberal segundo o autor está no atual modelo de acumulação de capitais. Sustentado por ciclos de especulação financeira e pela ideologia neoliberal, este modelo vem se reproduzindo à custa do desemprego de milhares de pessoas, do endividamento de famílias, da expropriação da natureza, da violação de direitos humanos 
etc. Mas, o que a crise financeira de 20082010 tem a ver com o colapso do sistema político formal de diversos países? Qual a relação entre a quebra do mercado de hipotecas dos EUA e a "onda de indignação" que se formou na Europa? O que Castells brilhantemente mostra nesse livro é a falácia da ideologia neoliberal, isto é, aquela que tenta nos convencer de que o Estado não deve intervir nos mercados, quando na realidade em todos os cantos da Europa o que se viu foi o alinhamento dos governos e da União Europeia ao mercado financeiro e a imposição de políticas de austeridade fiscal para sair da crise.

Por outro lado, essas medidas exigiram muitos sacrifícios dos cidadãos que, quando impingidos a pagar a conta, se movimentaram cada um à sua forma. Na França, caudatária do ideal de igualdade, a resposta dos indignados se deu por meio da formação de um forte movimento antiglobalização, da rejeição maciça aos partidos tradicionais franceses e da negação aos partidos neofacistas. Na Espanha a resposta deu origem ao 15-M, movimento social que teve início em 15 de maio de 2011 e ocupou as praças das principais cidades com reivindicações de todo tipo. Castells afirma que o pedido por "¡Democracia Real Ya!" era o único ponto comum entre os manifestantes espanhóis. Já no Reino Unido, a crise econômica gerou o referendo do Brexit, uma campanha em prol da saída do país da União Europeia, o qual exigia o controle das fronteiras territoriais e a rejeição à imigração de cidadãos da própria União Europeia. A imigração passou "a ser símbolo da invasão da vida cotidiana pela globalização em todas as suas dimensões" (CASTELLS, 2018 p.63). Nesse processo fica evidente a profunda divisão de classe, raça e cultura que define as sociedades ocidentais e que ameaça a democracia, uma vez que a universalização da "cidadania europeia" não é praticada pela maioria das pessoas.

Por isso, o voto a favor do Brexit não foi um voto de classe no sentido tradicional, mas um voto dos que, na terminologia empregada na campanha, se sentem abandonados à própria sorte (left behind) e marginalizados pela aceleração da mudança tecnológica, econômica e institucional, sem que as instituições que regulam suas vidas coevoluam adequadamente, mediante novas formas de representação. (CASTELLS, 2018, p.66)

Considerando o esgotamento do sistema político formal e a crise de legitimidade, os quais se manifestaram de diferentes formas nas democracias estudadas, Castells identifica alguns pontos comuns subjacentes à ruptura da ordem político-liberal que contribuem para manter acesa a chama da esperança.

O primeiro ponto é que diante do rechaço aos partidos tradicionais e suas formas corruptas de fazer política há uma busca incessante pela legitimidade perdida. Tanto os grupos conservadores de direita - que defendem o patriarcado, a misoginia, o racismo, a xenofobia, o neonazismo e o antissemitismo - quanto os grupos de esquerda - que ameaçam o establishment político por proporem formas alternativas de fazer política - buscam impedir o colapso de uma ordem política e de suas instituições.

Castells nos mostra que a reconstrução da legitimidade social de um representante político pode ser feita pela oposição às instituições deslegitimadas, pelo distanciamento entre o candidato e o próprio partido político, pela imposição do medo - principalmente aos setores mais vulneráveis da sociedade —, pela promessa do retorno ao Estado como centro de decisão e não mais às redes globais e supranacionais, e pelo acionamento de valores que tem como base a família patriarcal, a religião e o ultranacionalismo. Esses traços caracterizam, por exemplo, a eleição de Donald Trump à presidência dos EUA.

A nova legitimidade funciona por oposição. E se constrói em torno de um discurso que projeta uma rejeição geral ao estado das coisas, prometendo a salvação por meio da ruptura com essa ordem incrustada nas instituições e com essa cultura das elites cosmopolitas, suspeitas de desmantelar as últimas defesas da tribo ante a invasão do desconhecido. (CASTELLS, 2018, p.38)

Contudo, outro ponto comum da crise de legitimidade política é o que pode levar à emergência de novos atores políticos, que organizam suas práticas a partir de valores progressistas alternativos e reivindicam a democracia em suas próprias práticas. Aqui é 
importante observar como o contexto social, político e econômico é determinante para a emergência dessa forma de ação política. Nesse sentido, a perda de direitos sociais pós-crise de 2008 , as altas taxas de desemprego, a alta dos alugueis, a convivência com a precariedade urbana e a insatisfação popular com as condições de vida em geral foram elementos mobilizadores desses novos atores no caso espanhol. Ao construir outras práticas políticas como ocupação de praças, assembleias deliberativas, debates públicos urbanos com interação constante no espaço público digital e presença constante nas redes de internet; esses atores ameaçam o establishment político. Mais do que isso, se as instituições são o espelho da sociedade, ao propor outras práticas questiona-se o que está instituído e ascende-se a chama da esperança mencionada acima. Para chegar a esses apontamentos, o autor partiu do estudo do Podemos ${ }^{2}$ e suas confluências.

A experiência histórica nos mostra que do fundo da opressão e do desespero surgem, sempre, movimentos sociais de diferentes formas que mudam as mentes e, através delas, as instituições... Mas também sabemos que, até agora, as mudanças profundas demandaram uma substituição institucional a partir da transformação das mentes. E é nesse nível, o político-institucional propriamente, que o caos continua imperando. Daí a esperança, abrigada por milhões, de uma nova política. (CASTELLS, 2018, p.146)

A democracia está em crise e certamente precisa ser reinventada. Em tempos em que o autoritarismo se arvora mundo afora e a acumulação capitalista se dá, cada vez mais, por meio da violência, este livro é indispensável para lembrarmos que, embora a democracia jamais tenha assegurado direitos universais no capitalismo, é só nela que se torna possível superar a alienação política e enfrentar as desigualdades sociais. ,

\section{Referências}

CASTELLS, M. Ruptura - A crise da democracia liberal. $1^{\text {a }}$ Edição, Rio de Janeiro: Editora Zahar, 2018.

CASTELLS, M. A questão Urbana. Trad. Arlene Caetano. Rio de Janeiro, Paz e Terra, 1983.

CHIRIO, M. Eleição de Bolsonaro marca fim da Nova República, diz historiadora. São Paulo, 2018. Folha de São Paulo online. Entrevista concedida a Lucas Neves. Disponível em: https://www1.folha.uol. com.br/ilustrissima/2018/11/eleicao-de-bolsonaromarca-fim-da-nova-republica-diz-historiadora.shtml Acesso em 25/02/19.

\footnotetext{
2 Partido de esquerda articulado por diversas formações da Espanha, oriundo dos mais variados movimentos, das diversas nacionalidades e regiões que se constituiu a partir de janeiro de 2014.
} 